\title{
Magneto-Ionics in Single-Layer Transition Metal Nitrides
}

Julius de Rojas, Joaquín Salguero, Fatima Ibrahim, Mairbek Chshiev, Alberto Quintana, Aitor Lopeandia, Maciej O. Liedke, Maik Butterling, Eric Hirschmann, Andreas Wagner, Llibertat Abad, José L. Costa-Krämer, Enric Menéndez,* and Jordi Sort*

Cite This: ACS Appl. Mater. Interfaces 2021, 13, 30826-30834

Read Online

山ll Metrics \& More

国 Article Recommendations

Supporting Information

(7) Propylene Carbonate $\oplus \mathrm{Na}^{+}$ magnetism by voltage-driven transport of ions, traditionally oxygen or lithium and, more recently, hydrogen, fluorine, or nitrogen. Here, magneto-ionic effects in single-layer iron nitride films are demonstrated, and their performance is evaluated at room temperature and compared with previously studied cobalt nitrides. Iron nitrides require increased activation energy and, under high bias, exhibit more modest rates of magneto-ionic motion than cobalt nitrides. $\mathrm{Ab}$ initio calculations reveal that, based on the atomic bonding strength, the critical field required to induce nitrogen-ion motion is higher in iron nitrides $\left(\approx 6.6 \mathrm{~V} \mathrm{~nm}^{-1}\right)$ than
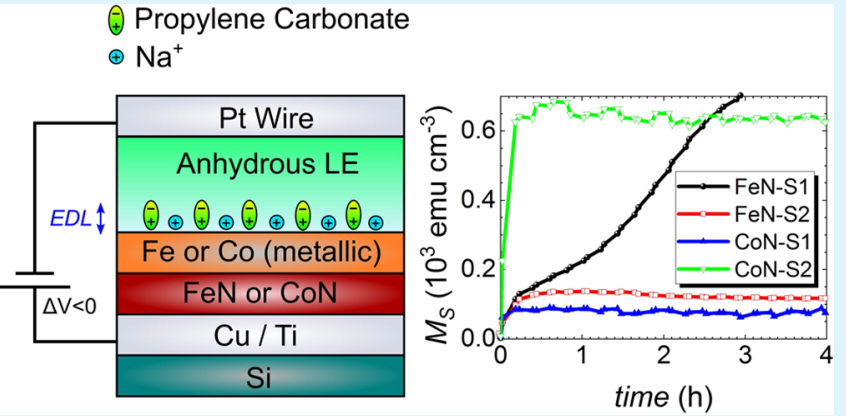
in cobalt nitrides $\left(\approx 5.3 \mathrm{~V} \mathrm{~nm}^{-1}\right)$. Nonetheless, under large bias (i.e., well above the magneto-ionic onset and, thus, when magneto-ionics is fully activated), iron nitride films exhibit enhanced coercivity and larger generated saturation magnetization, surpassing many of the features of cobalt nitrides. The microstructural effects responsible for these enhanced magneto-ionic effects are discussed. These results open up the potential integration of magneto-ionics in existing nitride semiconductor materials in view of advanced memory system architectures.

KEYWORDS: voltage control of magnetism, magneto-ionics, electrolyte gating, transition metals, metal nitrides, nitrogen ions, open volume defects, positron annihilation spectroscopy

\section{INTRODUCTION}

Modern electronic devices store data using electric current to manipulate the magnetization orientation of magnetic domains. With device miniaturization pushing nominal device dimensions toward $10 \mathrm{~nm}$, greater amounts of energy are expended due to resistive heating and device cooling. This challenge has spurred research toward discovering novel materials and developing new devices for next-generation technologies with improved energy efficiency, robust thermal stability, and precise control of magnetic properties. Voltagecontrolled magnetism (VCM) tackles this challenge by replacing electric current with an applied voltage, potentially leading to significant energy savings. ${ }^{1,2}$ Magneto-ionics, ${ }^{3-18}$ a branch of VCM in which ions such as $\mathrm{O}^{2-}, \mathrm{H}^{+}, \mathrm{Li}^{+}, \mathrm{F}^{-}$, or $\mathrm{N}^{2-/ 3-}$ are injected into and withdrawn from a target material under an applied bias, has been shown to be capable of generating large, nonvolatile, and reproducible modulations of bulk magnetic observables. A typical magneto-ionic structure is composed of a ferromagnetic layer in contact with an oxide reservoir layer from which oxygen ions are transported, modifying the target material's structure and stoichiometry, with corresponding changes in coercive field, exchange bias field, magnetic easy axis, or magnetic anisotropy. ${ }^{8-10,12,17,19-23}$ Cyclability remains an issue as ionic transport may result in irreversible structural changes. Recently, ionic motion on the order of $10^{3} \mathrm{~Hz}$ has been successfully demonstrated with good endurance via a proton-based $\left(\mathrm{H}^{+}\right)$mechanism, albeit with some limitations in the operational film thicknesses and hydrogen retention. ${ }^{11}$

Recent studies of the magneto-ionic properties of singlelayer thin films with structural oxygen $\left(\mathrm{Co}_{3} \mathrm{O}_{4}\right)$ or nitrogen $(\mathrm{CoN})$ ions, present in the as-prepared thin-film state, have demonstrated that fully reversible and cyclable magnetic transitions between a nonferromagnetic (OFF) and a ferromagnetic state $(\mathrm{ON})$ are indeed possible. ${ }^{5,12,24}$ Interestingly, and in contrast to the diffusion channels observed in $\mathrm{Co}_{3} \mathrm{O}_{4}, \mathrm{CoN}$ films transport nitrogen via a planar ion migration front and possess both superior cyclability and lower operating voltages than $\mathrm{Co}_{3} \mathrm{O}_{4}{ }^{24}$ hinting that metal nitrides may compare favorably with their metal oxide counterparts. Previous $a b$ initio calculations of the enthalpy of formation

Received: April 2, 2021

Accepted: June 9, 2021

Published: June 22, 2021 
of CoN have predicted values of $\Delta H_{\mathrm{f}} \approx-50 \mathrm{~kJ} \mathrm{~mol}{ }^{-1}, 25$ significantly higher (i.e., less negative) than experimental estimates conducted on $\mathrm{CoO}$ and $\mathrm{Co}_{3} \mathrm{O}_{4}$ of $\Delta H_{\mathrm{f}} \approx-237.9$ and $-910.02 \mathrm{~kJ} \mathrm{~mol}^{-1}$, respectively. ${ }^{26-28}$ This is consistent with the difference in electronegativity between nitrogen and oxygen: the lower electronegativity of nitrogen results in weaker bonds with Co cations, suggesting increased magneto-ionic mobility. Properly tuned FeN may be a tantalizing alternative target material for magneto-ionics, as ab initio calculations show that the enthalpy of formation of $\mathrm{FeN}$ is comparable to that of $\mathrm{CoN}$ and significantly higher (i.e., less negative) than that of $\mathrm{FeO} .^{25,29}$ In addition, magnetic nitrides ${ }^{30,31}$ such as $\mathrm{Fe}-\mathrm{N}^{32-37}$ have recently drawn significant research interest due to their array of desirable properties, including high hardness, melting point, incompressibility, cost efficiency, and greater magnetization than iron oxides, ${ }^{38-43}$ another class of magneto-ionic target materials. ${ }^{18,21,23}$ Iron nitrides also span a wide range of mechanical and magnetic properties, which can be tuned by varying the nitrogen concentration in $\mathrm{Fe}_{x} \mathrm{~N}_{y},{ }^{44-47}$ and can be easily integrated with semiconductor electronics. These factors, along with the relative abundance of $\mathrm{Fe}$ over $\mathrm{Co},{ }^{48}$ suggest iron nitride could be a prime candidate for magneto-ionics.

In this work, voltage-driven nitrogen transport in iron nitride films is demonstrated, and the magneto-ionic performance is evaluated and compared with cobalt nitride films. The iron nitride films are found to have, under large bias (i.e., well above the magneto-ionic onset voltage and, thus, when magnetoionics is fully activated), greater total magnetizations, larger coercive fields, lower magneto-ionic rates, and lower (i.e., more negative) onset voltages than the examined cobalt nitrides $(-8$ vs $-4 \mathrm{~V})$. The microstructural effects responsible for the enhanced magneto-ionically induced coercivity and magnetization in iron nitride films are discussed, while ab initio calculations reveal that the formation energy of $\mathrm{FeN}$ requires a greater critical field $\left(\approx 6.6 \mathrm{~V} \mathrm{~nm}^{-1}\right)$ to induce magneto-ionic motion than $\mathrm{CoN}\left(\approx 5.3 \mathrm{~V} \mathrm{~nm}{ }^{-1}\right)$, consistent with the experimentally observed voltages needed to initiate magnetoionics.

\section{RESULTS AND DISCUSSION}

Iron nitride $(\mathrm{FeN})$ and cobalt nitride $(\mathrm{CoN})$ films $(85 \mathrm{~nm})$ were grown atop $\mathrm{Cu}(60 \mathrm{~nm}) / \mathrm{Ti}(20 \mathrm{~nm}) /\left[\begin{array}{lll}1 & 0 & 0\end{array}\right]$-oriented $\mathrm{Si}$ substrates. Deposition of iron and cobalt was performed using nitrogen partial pressures of $25 \%$ and $50 \%$, respectively, resulting in differing nanocrystallinities and electrical transport behavior. To distinguish between the films by nitrogen partial pressure and relative electric resistivity, they are labeled $\mathrm{FeN}-$ S1, FeN-S2, Co-S1, and Co-S2 (see Table 1).

Structural characterization of the films was carried out using $\theta / 2 \theta$ X-ray diffraction (XRD). Figure la shows the XRD patterns of the as-prepared iron nitride films. The nearly stoichiometric FeN films (i.e., FeN-S1, FeN-S2) exhibit a single peak which is consistent with the $\left(\begin{array}{lll}1 & 1 & 1\end{array}\right)$ textured hexagonal close-packed (hcp) $P 6_{3} / m m c$ FeN diffraction peak (Materials Project ID 12120) or possibly the (llll $\left.\begin{array}{lll}0 & 1\end{array}\right)$ facecentered cubic (fcc) $\bar{F} \overline{4} \mathrm{~m}$ FeN diffraction peak (Materials Project ID 6988). ${ }^{49}$ The patterns also show the $\left(\begin{array}{lll}1 & 1 & 1\end{array}\right) \mathrm{Cu}$ peak arising from the buffer layer. Rietveld refinement of the FeN XRD patterns reveals that the hcp phases of both films are distorted, and the films are highly nanocrystalline, with the smallest crystallite sizes in the range of 10-14 nm.. The nitrogen content is estimated by electron energy loss spectroscopy (EELS) (see Table 1). As reported earlier, ${ }^{24}$
Table 1. Iron and Cobalt Nitride Films, Argon/Nitrogen Partial Pressure during Deposition, Crystallite Size, and Resistivity at Room Temperature ${ }^{a}$

$\begin{array}{ccccc}\mathrm{Co}-\mathrm{N} & \begin{array}{c}\mathrm{P}_{\mathrm{N} 2} \\ (\%)\end{array} & \begin{array}{c}\mathrm{N} \text { concentration } \\ (\%)\end{array} & \begin{array}{c}\langle D\rangle \\ (\mathrm{nm})\end{array} & \begin{array}{c}\rho(T=300 \mathrm{~K}) \\ (\mu \Omega \cdot \mathrm{cm})\end{array} \\ \mathrm{FeN}-\mathrm{S} 1 & 25 & 49 & 10 & 304 \\ \mathrm{FeN}-\mathrm{S} 2 & 50 & 51 & 14 & 509 \\ \mathrm{CoN}-\mathrm{S} 1 & 25 & 33 & 9 & 156 \\ \mathrm{CoN}-\mathrm{S} 2 & 50 & 50 & 13 & 411\end{array}$

${ }^{a}$ Crystallite sizes obtained from Rietveld refinement of the X-ray diffraction patterns. ${ }^{51}$ For comparison, the resistivities of pure $\mathrm{Fe}$ and Co films are 21 and $11 \mu \Omega \cdot \mathrm{cm}$, respectively (measured at room temperature).
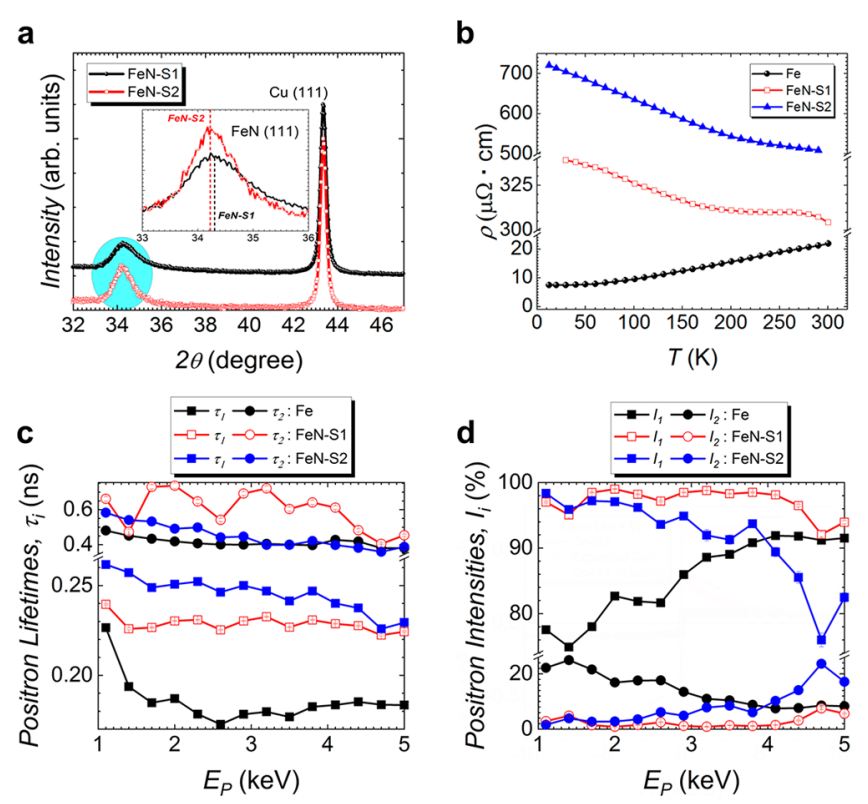

Figure 1. Structural, transport, and defect characterization of iron nitride films. (a) $\theta / 2 \theta$ XRD diffraction patterns of the as-prepared iron nitride films. (b) Resistivity $\rho$ measured as a function of temperature from 20 to $300 \mathrm{~K}$ for all as-prepared iron nitride films. (c and d) Positron lifetime components $\tau_{i=1-2}$ and their relative intensities $I_{i=1-2}$ as a function of positron implantation energy $E_{P}$ for all as-prepared iron nitride films.

the CoN-S2 film exhibits a single peak which is consistent with the ( $\left(\begin{array}{lll}1 & 1 & 1\end{array}\right)$ diffraction peak of the expanded Fm3m cubic CoN phase (see Figure S1), while CoN-S1 shows a peak consistent with hexagonal ( $\left.\begin{array}{lll}1 & 0 & 1\end{array}\right) \mathrm{Co}_{3} \mathrm{~N}_{1+x}$ phase. ${ }^{50}$ Crystallite size and nitrogen concentration values are listed for comparison (Table 1).

Resistivity measurements as a function of temperature (20$300 \mathrm{~K}$ ) were performed on both as-prepared FeN films as well as purely metallic iron for reference (Figure $1 \mathrm{~b}$ ). The resistivity $\rho$ at room temperature ranges from $\approx 21 \mu \Omega \cdot \mathrm{cm}$ in pure Fe to $\approx 500 \mu \Omega \cdot \mathrm{cm}$ in FeN-S2, increasing gradually with $\mathrm{N}$ content, as expected. The pure iron film shows a monotonic increase of resistivity throughout the temperature range $(\mathrm{d} \rho / \mathrm{d} T>0$, where $\rho$ and $T$ are resistivity and temperature, respectively), consistent with metallic behavior. In the case of FeN-S2 (Figure $1 \mathrm{~b}$ ), resistivity is observed to monotonically decrease $(\mathrm{d} \rho / \mathrm{d} T<0)$ throughout the temperature range, consistent with semiconducting behavior. In contrast with $\mathrm{FeN}-\mathrm{S} 2$, $\mathrm{FeN}-\mathrm{S} 1$ has an overall lower resistivity than $\mathrm{FeN}-\mathrm{S} 2$ with the sign of $\mathrm{d} \rho / \mathrm{d} T$ negative up to $220 \mathrm{~K}$, then basically zero up to 
$270 \mathrm{~K}$, and finally negative to $300 \mathrm{~K}$. This exhibits a semiconducting contribution and thus a more complex transport behavior than a typical insulating film. These relative differences in behavior mark the FeN-S1 film as relatively conductive and the FeN-S2 film as relatively resistive. CoNS2 exhibits a similar transition in electrical transport behavior (see Table 1, Figure S2), whereas $\mathrm{CoN}-\mathrm{S} 1$ is rather conductive, although with a higher electric resistivity than metallic Co.

In order to characterize the depth-dependent defect structure of the as-prepared iron nitride films, variable energy positron annihilation lifetime spectroscopy (VEPALS) experiments were conducted. ${ }^{52-57}$ Contributions from positron annihilation lifetimes ${ }^{12} \tau_{1}$, corresponding to localized vacancies, and $\tau_{2}$, corresponding to a mixture of signals from surface states and grain boundaries, are seen in both films (Figure 1c and $1 \mathrm{~d})$. The annihilation lifetimes, $\tau_{i}$, decrease as the positrons penetrate deeper into the film, ascribed to an increase in vacancy size close to the electrolyte-side surface of the $\mathrm{FeN}$ films and a decrease in vacancy size deeper in the films, rendering a graded defect structure. The positron lifetimes, $\tau_{1}$ and $\tau_{2}$, increase with resistivity, indicating that resistivity is tightly related to vacancy and grain boundary formation (i.e., the nanostructuring of the films). Examining the as-prepared FeN-S1 film, only contributions from $\tau_{1}$ and $\tau_{2}$ are observed, with no contributions from lifetime $\tau_{3}$ ("voidlike" structures) present. $^{12} \tau_{1}$, representing small vacancy clusters, reaches a maximum of $\approx 0.24$ ns near the surface, before dropping to $\approx 0.23 \mathrm{~ns}$ in the film region (Figure $1 \mathrm{c}$, open squares). This suggests a higher density larger defect complex size consisting of 3-4 vacancies within a cluster near the top of the film and 2-3 vacancies within a cluster near the working electrode (see Figure S3 for details). $\tau_{2}$, representing a convolution of surface states (subsurface region) and grain boundaries, remains above $0.4 \mathrm{~ns}$ throughout the film, indicating the presence of larger vacancy clusters and small voids near the surface. FeN-S1 shows a residual contribution from larger vacancy complexes, whereas $\mathrm{FeN}-\mathrm{S} 2$ exhibits a larger density of open volumes closer to the interface with the buffer layer. The relative intensity $I_{1}$ 's more rapid decrease $\left(I_{2}\right.$ increases) is consistent with the appearance of the increasing influence of the $\mathrm{Cu}$ and $\mathrm{Ti}$ layers as the positron implantation energy approaches $E_{\mathrm{p}}=4 \mathrm{keV}$ (Figure 1d). This overall behavior of both of the as-prepared iron nitride films in the VEPALS measurements shows that FeN-S1 and FeN-S2 are comparable to the as-prepared state of $\mathrm{CoN}-\mathrm{S} 2$ (Figure S4) with slightly lower lifetimes.

All magneto-ionic measurements were preformed using a liquid electrolyte (i.e., propylene carbonate with $\mathrm{Na}^{+}$) in a capacitor-like configuration (Figure $2 \mathrm{a}$ ), where the $\mathrm{Cu} / \mathrm{Ti}$ buffer layer acts as a working electrode and the Pt wire acts as a counter electrode. The use of a nonaqueous, aprotic polar liquid electrolyte will prevent electrochemical oxidation during voltage biasing. ${ }^{5,10,12,24}$ This configuration generates an electric double layer (EDL) at the film surface which applies a uniform, out-of-plane electric field. ${ }^{5,10,58-62}$ In-plane measurements of $M-H$ hysteresis loops, spanning the range between -20 and $20 \mathrm{kOe}$, were measured using a vibrating sample magnetometer. The upper and lower branches were measured in 12.5 min for a total of $25 \mathrm{~min}$ for each major loop. As-prepared $\mathrm{FeN}-\mathrm{S} 1, \mathrm{Fe}-\mathrm{S} 2$, CoN-S1, and CoN-S2 films show residual ferromagnetic behavior and a saturation magnetization $M_{S}$ between 3 and $12 \mathrm{emu} \mathrm{cm}^{-3}$ corresponding to contamination

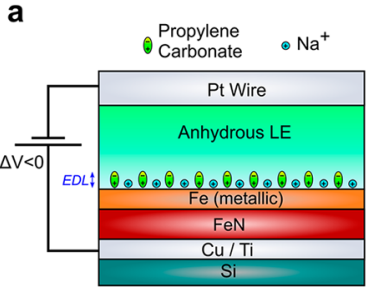

C

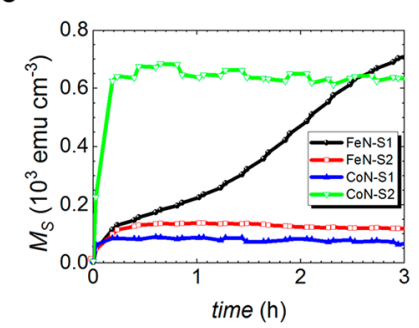

b

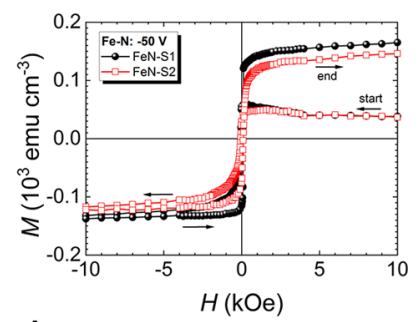

d

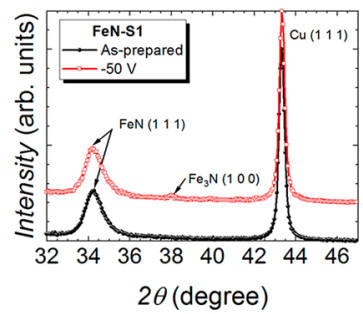

Figure 2. Magneto-ionic characterization of iron nitride films by inplane vibrating sample magnetometry under electrolyte gating. (a) Schematic of the capacitor-like structure used during the measurement of each film. Anhydrous liquid electrolyte (LE) forms an electric double layer (EDL) at the film surface. Thin layer of metallic iron is drawn to represent the appearance of a ferromagnetic layer after voltage actuation. (b) First hysteresis loops under $-50 \mathrm{~V}$ bias for iron nitride films. (c) Saturation magnetization $\left(M_{\mathrm{S}}\right)$ measured as a function of time for iron nitride and cobalt nitride films, taken from $M-H$ loops measured between -20 and $20 \mathrm{kOe}$. (d) $\theta / 2 \theta$ XRD diffraction patterns of $\mathrm{FeN}-\mathrm{S} 1$ before and after $-50 \mathrm{~V}$ biasing treatment for $75 \mathrm{~min}$.

of $<0.70 \%(0.42 \%)$ by volume of metallic iron (cobalt), a result of off-stoichiometric regions in the film and/or ferromagnetic impurities in the substrate (Figures S5a and S5b). Magnetoionic rates were assessed by measuring magnetic hysteresis loops as a voltage of $-50 \mathrm{~V}$ was applied across the film.

The first $M-H$ hysteresis loop measured for each iron nitride film is shown in Figure $2 b$. The films clearly demonstrate the appearance of a ferromagnetic phase with an increase in $M_{\mathrm{S}}$ and the coercive field $H_{\mathrm{C}}$. During the first loop the magnetization of both $\mathrm{FeN}-\mathrm{S} 1$ and $\mathrm{FeN}-\mathrm{S} 2$ clearly increases, although more in $\mathrm{FeN}-\mathrm{S} 1$ than in $\mathrm{FeN}-\mathrm{S} 2$ (Figure 2b).

The first two loops measured during $-50 \mathrm{~V}$ biasing are plotted in Figure $\mathrm{S} 5 \mathrm{c}-\mathrm{f}$, so that the changes in magnetic behavior can be more clearly observed for all films. In Figure $2 c$, the overall change in $M_{S}$ is plotted as a function of time for $\mathrm{FeN}-\mathrm{S} 1, \mathrm{FeN}-\mathrm{S} 2, \mathrm{CoN}-\mathrm{S} 1$, and $\mathrm{CoN}-\mathrm{S} 2$. Cobalt nitride films are included for ease of comparison. For CoN-S2 and FeN-S2 films, $M_{\mathrm{S}}$ quickly increases during the initial stages of voltage application (first $12 \mathrm{~min}$, Figure $2 \mathrm{c}$ ) and subsequently levels off. Interestingly, $\mathrm{FeN}-\mathrm{S} 1$ exhibits a distinct multistep process: in the first stage, $M_{S}$ increases at a rate on the order of FeN-S2, which can be ascribed to the formation of a ferromagnetic $\mathrm{Fe}_{3} \mathrm{~N}$ phase (Figure 2d), before continuing to increase, albeit at a slower rate, up to a maximum $M_{\mathrm{S}}(898 \mathrm{emu}$ $\left.\mathrm{cm}^{-3}\right)$. The $M_{\mathrm{S}}$ values reached by each film after long-term biasing $(6 \mathrm{~h})$ are presented in Table 2 . The initial slope of the magnetization was fitted using a linear regression with rates found to be $502 \mathrm{emu} \mathrm{cm} \mathrm{cm}^{-3} \mathrm{~h}^{-1}$ for FeN-S1 and $267 \mathrm{emu} \mathrm{cm}^{-3}$ $\mathrm{h}^{-1}$ for FeN-S2, evidencing magneto-ionics in FeN, although with lower rates than $\mathrm{CoN}-\mathrm{S} 1$ and $\mathrm{CoN}-\mathrm{S} 2$ (Table 2). 
Table 2. Magneto-Ionic Rates, Saturation Magnetization, Squareness (Ratio of Remanence to Saturation $M_{a g n e t i z a t i o n, ~} M_{\mathrm{R}} /$ $M_{S}$ ), Normalized Slope at the Coercive Field, and Coercive Field of Treated Iron and Cobalt Nitride Films ${ }^{a}$

\begin{tabular}{|c|c|c|c|c|c|}
\hline $\mathrm{Co}-\mathrm{N}$ & $\mathrm{d} M / \mathrm{d} t\left(\mathrm{emu} \mathrm{cm}^{-3} \mathrm{~h}^{-1}\right)$ & $M_{\mathrm{S}}\left(\mathrm{emu} \mathrm{cm} \mathrm{c}^{-3}\right)$ & $M_{\mathrm{R}} / M_{\mathrm{S}}(\%)$ & $1 / M_{\mathrm{S}} \mathrm{d} M / \mathrm{d} H @ \mathrm{HC}\left(\mathrm{kOe}^{-1}\right)$ & $H_{\mathrm{C}}(\mathrm{Oe})$ \\
\hline $\mathrm{FeN}-\mathrm{S} 1$ & 502 & 898 & 87 & 17 & 86 \\
\hline $\mathrm{FeN}-\mathrm{S} 2$ & 267 & 137 & 63 & 5 & 140 \\
\hline $\mathrm{CoN}-\mathrm{S} 1$ & 1012 & 90 & 84 & 21 & 65 \\
\hline $\mathrm{CoN}-\mathrm{S} 2$ & 2602 & 637 & 96 & 97 & 17 \\
\hline
\end{tabular}

${ }^{a}$ Values listed reached after $6 \mathrm{~h}$ of gating under $-50 \mathrm{~V}$ bias.

CoN-S2 shows a tremendous increase in $M_{\mathrm{S}}$ while sweeping through the first quadrant of the hysteresis loop under bias, greater than $\mathrm{FeN}-\mathrm{S} 1$ and $\mathrm{FeN}-\mathrm{S} 2$. Both cobalt nitride films show clear increases in $M_{\mathrm{S}}$ as a function of time with rates of $1012 \mathrm{emu} \mathrm{cm}^{-3} \mathrm{~h}^{-1}$ for CoN-S1 and $2602 \mathrm{emu} \mathrm{cm}^{-3} \mathrm{~h}^{-1}$ for $\mathrm{CoN}-\mathrm{S} 2$ and $\mathrm{CoN}-\mathrm{S} 1$ and $\mathrm{CoN}-\mathrm{S} 2$ reaching final values of $M_{\mathrm{S}}$ near 90 and $637 \mathrm{emu} \mathrm{cm}^{-3}$, respectively.

The lower magneto-ionic rates of iron nitrides can be attributed to a convolution of several factors: a slightly lower enthalpy of formation of $\mathrm{FeN}$, requiring greater energy to break the bonds between iron and nitrogen, ${ }^{25,63}$ reduced positron lifetimes $\tau_{1}$ and $\tau_{2}$, which can be correlated with smaller vacancy clusters and grain boundaries and thus a reduced ionic mobility, and variation in electrical transport properties. An increase in the required energy to separate $\mathrm{Fe}$ and $\mathrm{N}$ in turn requires a greater applied electric field (voltage) to the film, reducing the ionic drift velocity at a given voltage when compared with cobalt nitride. Smaller vacancies and grain boundaries (cross sections) reduce the conductivity of the ionic pathways, requiring greater voltage to transfer ions through the film, again reducing the drift velocity at a given voltage when compared with cobalt nitride. A higher resistivity allows the applied electric field to penetrate deeper into the film, which most likely boosts magneto-ionic rates. Higher resistivity can also be correlated with increased bonding between $\mathrm{Fe}$ and $\mathrm{N}$, thereby increasing the energy required to begin ionic motion and thus reducing magneto-ionic rates. A balance between these factors must be achieved to optimize magneto-ionic performance. Since FeN-S1 shows a greater magneto-ionic rate than $\mathrm{FeN}-\mathrm{S} 2$, XRD diffraction was carried on the FeN-S1 film post-treatment (Figure 2d). After biasing at $-50 \mathrm{~V}$ for $75 \mathrm{~min}, \mathrm{FeN}-\mathrm{S} 1$ shows traces of a new peak compatible with an iron nitride with lower nitrogen concentration: ( $\left.\begin{array}{lll}1 & 0 & 0\end{array}\right) \mathrm{Fe}_{3} \mathrm{~N}$ (PDF 00-001-1236) or ( $\left.\begin{array}{lll}1 & 0 & 0\end{array}\right)$ $\mathrm{Fe}_{2} \mathrm{~N}$ (PDF 00-002-1206). Indeed, the increase of magnetization $M_{\mathrm{S}}$ of $\mathrm{FeN}-\mathrm{S} 1$ as nitrogen is removed from the film can be correlated with the appearance of a magnetic $\mathrm{Fe}_{3} \mathrm{~N}$ phase, whose magnetic moment has been calculated ab initio to be on the order of $1.44 \mu_{\mathrm{B}}{ }^{64}$ After long-term voltage application, the $M_{\mathrm{S}}$ of $\mathrm{FeN}-\mathrm{S} 1$ is found to be larger than the $M_{S}$ of the Co nitrides. Considering that the ratios of Fe:N and Co: $\mathrm{N}$ are nearly identical, this can be attributed to the larger magnetic moment per atom of metallic $\mathrm{Fe}\left(2.22 \mu_{\mathrm{B}}\right)$ compared to metallic Co $\left(1.72 \mu_{\mathrm{B}}\right){ }^{48}$ which becomes increasingly present as more and more nitrogen is removed from the system.

The evolution of the shape of the $M-H$ loops under bias can also provide key insights into the differences between the generated ferromagnetic phases. The squareness, defined as the ratio of the remanence, $M_{R}$, to $M_{S}\left(M_{R} / M_{S}\right)$, the slope of the hysteresis loop at the coercive field, $H_{\mathrm{C}}$, normalized to $M_{\mathrm{S}}$ $\left(M_{\mathrm{S}}{ }^{-1} \mathrm{~d} M / \mathrm{d} H\left[H=H_{\mathrm{C}}\right]\right)$, and $H_{\mathrm{C}}$ have been assessed for each branch of the measured $M-H$ loops as a function of time (Figure S6a-f). The asymptotic values of the magnetic parameters reached by the iron and cobalt nitride films after $6 \mathrm{~h}$ of biasing at $-50 \mathrm{~V}$ are reported in Table 2. Broadly, greater squareness and lower coercive fields indicate a steeper slope of the $M-H$ curve and a narrower, more uniform coercive field distribution. ${ }^{65} \mathrm{FeN}-\mathrm{S} 1$ demonstrates lower squareness and a higher coercive field than $\mathrm{CoN}-\mathrm{S} 2$ (Figure S6), correlating with a less uniform coercive field distribution than $\mathrm{CoN}-\mathrm{S} 2$. The coercive fields of each film also reflect intrinsic differences in the generation of magnetic states. The coercive fields of $\mathrm{FeN}-\mathrm{S} 2$ and $\mathrm{CoN}-\mathrm{S} 1$ monotonically reach the highest values of the iron and cobalt films, respectively (140 and $65 \mathrm{Oe}$ ). This can perhaps be attributed to a paramagnetic to ferromagnetic transition or possibly the formation of a high density of small, isolated clusters developing from the superparamagnetic state of small, weakly coupled grains in a nonmagnetic nitride matrix. The behavior of $\mathrm{FeN}-\mathrm{S} 1$ and $\mathrm{CoN}-\mathrm{S} 2$ (Figure S6) resembles the wellknown variation of coercivity with increasing size of a single particle, first increasing from a superparamagnetic to a single domain state and then decreasing $\mathrm{H}_{\mathrm{C}}{ }^{65}$ as the multidomain state is reached. FeN-S1 and CoN-S2 differ, however, in the maximum coercive field and time scales: $\mathrm{FeN}-\mathrm{S} 1$ reaches a larger coercive field $H_{\mathrm{C}}$ more slowly (148 Oe in $2 \mathrm{~h}$ vs $50 \mathrm{Oe}$ in $12 \mathrm{~min}$ in $\mathrm{CoN}-\mathrm{S} 2$ ). Both films asymptotically approach a lower coercivity with increasing biasing time. It should be noted that $\mathrm{FeN}-\mathrm{S} 1$ reaches a higher coercive peak than the coercive peaks of $\mathrm{CoN}-\mathrm{S} 1$ and $\mathrm{CoN}-\mathrm{S} 2$, suggesting that FeN-S1 may be more useful for magnetic memory applications, which often require magnetic stability. In general, both FeN films reached higher $H_{\mathrm{C}}$ values than either $\mathrm{CoN}$ film throughout the biasing process. This can be indicative of comparatively smaller activated magnetic regions, comprising single- or few-domain structures in mostly denitrided regions, perhaps the result of a less complete, planar ionic diffusion front in the iron nitride films.

To further understand the structural and compositional changes the iron nitride films undergo during gating, crosssectional lamellae of the as-prepared and treated FeN-S1 films, capped with a protective platinum layer, were characterized by high-angle annular dark-field scanning transmission electron microscopy (HAADF-STEM) and EELS. Images of $\mathrm{FeN}-\mathrm{S} 1$ are shown in Figure 3; analogous images of $\mathrm{CoN}-\mathrm{S} 2$ can be found in a previous work. ${ }^{24}$ The as-prepared FeN-S1 film is highly nanostructured and isotropic (Figure $3 a)$. Fe (red) and $\mathrm{N}$ (green) are homogeneously distributed in the films (Figure 3b), similar to the $\mathrm{CoN}-\mathrm{S} 2$ as-deposited films. After treatment with $-50 \mathrm{~V}$ for $75 \mathrm{~min}, \mathrm{FeN}-\mathrm{S} 1$ undergoes a moderate change, roughly corresponding to a more nanoporous structure closer to the electrolyte side and a highly nanostructured structure near the working electrode side, suggesting a moderate denitriding process (Figure 3c). A concentration front appears, reflected in the homogeneous presence of $\mathrm{Fe}$ and $\mathrm{N}$ (red and green, respectively) near the 


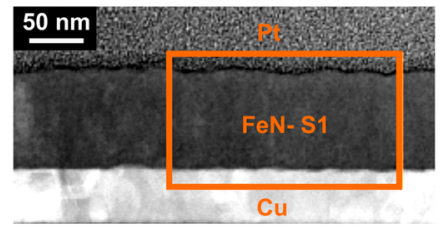

C

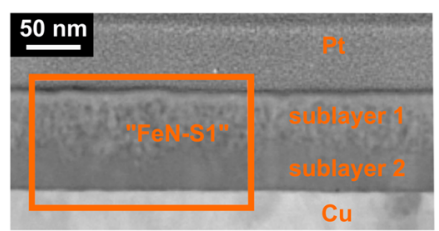

$\mathrm{Fe}$ b

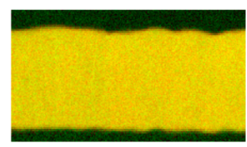

d

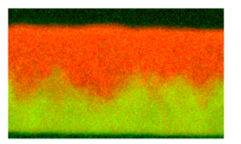

N

Figure 3. Structural and compositional characterization via high-angle annular dark-field scanning transmission electron microscopy (HAADF-STEM, left images) and electron energy loss spectroscopy (EELS, right images). HAADF-STEM and elemental EELS mappings corresponding to the areas marked in orange in as-prepared ( $a$ and $b$ ) FeN-S1and ( $c$ and d) FeN-S1 films negatively biased at $-50 \mathrm{~V}$ for $75 \mathrm{~min}$, respectively. Copper and platinum layers serve as the working electrode and a protective capping layer for lamellae preparation, respectively. Colors corresponding to each element are noted at the bottom of the figure.

electrode and the reduced presence of $\mathrm{N}$ (orange/red), consistent with the formation of $\mathrm{Fe}_{3} \mathrm{~N}$ near the electrolyte side (Figure 3d). Conversely, $\mathrm{CoN}-\mathrm{S} 2$ has been shown to undergo a dramatic change with almost complete denitriding under $-50 \mathrm{~V}$ for $75 \mathrm{~min}$ but again with a clearly defined concentration front appearing parallel to the surface. ${ }^{24}$ In $\mathrm{FeN}-\mathrm{S} 1$, the migration front is less defined but relatively planar without the existence of cross-sectional channels as happens in other magneto-ionic systems such as $\mathrm{Co}_{3} \mathrm{O}_{4}{ }^{12}$

Understanding the minimum voltage required to initiate magneto-ionic motion is key to evaluating the magneto-ionic performance, so the onset voltages were determined by monotonically increasing the applied bias in steps of $-2 \mathrm{~V}$ (for $25 \mathrm{~min}$ each) and noting when the films started to show an increase in ferromagnetic signal (Figure $4 a$ and $4 b$ ). Both the magnitude and the duration of the applied voltage affect the magneto-ionic response, so the measured threshold voltages should be taken as approximate values. Once a threshold voltage was reached (i.e., permanent magnetism is induced), the applied voltage was held for $75 \mathrm{~min}$ before inverting the polarity $(+8$ and $+4 \mathrm{~V}$, respectively). The onset voltage for $\mathrm{FeN}-\mathrm{S} 1$ and $\mathrm{FeN}-\mathrm{S} 2(-8 \mathrm{~V})$ is higher than that $\mathrm{Co}-\mathrm{S} 1$ and $\mathrm{CoN}-\mathrm{S} 2(-4 \mathrm{~V})$, and all films clearly recover the as-prepared $M_{\mathrm{S}}$ under inverted bias (i.e., $M_{\mathrm{S}}$ modulation is fully reversible). The measured onset voltages reflect a lower activation energy for $\mathrm{N}$ ion motion in cobalt nitrides than in iron nitrides, presumably due to the lower electronegativity between nitrogen and iron compared to cobalt (1.64 vs. $1.7)^{66,67}$ and an increased cohesive energy. ${ }^{25} \mathrm{FeN}-\mathrm{S} 1$ shows an excellent ability to completely recover not only the magnetization of as-grown film but also the squareness and slope at the coercive field (Figure S7), which could make it useful for practical applications.

CoN-S2 films were also examined via HDAAF-STEM and EELS after onset and recovery $(-4$ and $+4 \mathrm{~V})$ experiments

a

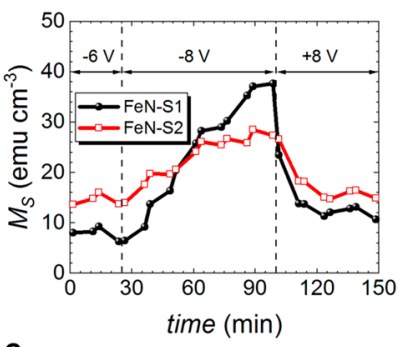

c

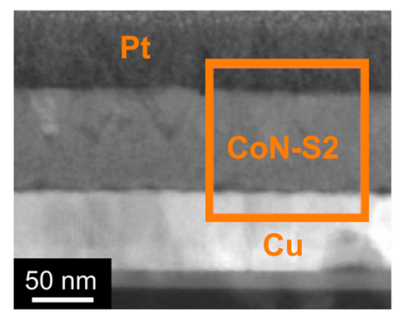

e

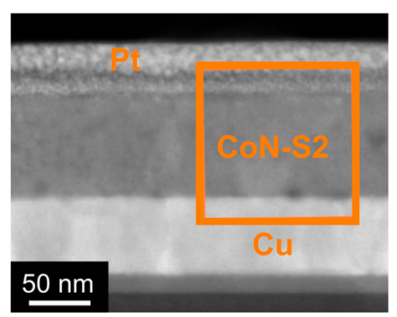

Co b

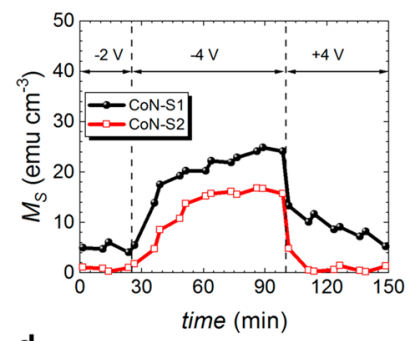

d

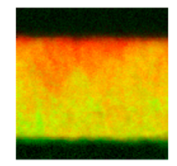

f

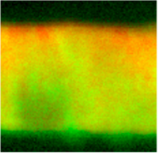

N

Figure 4. Magneto-ionic behavior of iron and cobalt nitrides during onset and recovery experiments. Structural and compositional characterization in CoN-S1 film using high-angle annular dark-field scanning transmission electron microscopy (HAADF-STEM) and electron energy loss spectroscopy (EELS). ( $a$ and b), Saturation magnetization $\left(M_{S}\right)$ as a function of time under applied onset and recovery voltages for $\mathrm{FeN}-\mathrm{S} 1, \mathrm{FeN}-\mathrm{S} 2$, and $\mathrm{CoN}-\mathrm{S} 1, \mathrm{CoN}-\mathrm{S} 2$. HAADF-STEM and elemental EELS mappings corresponding to the areas marked in orange in ( $\mathrm{c}$ and $\mathrm{d}$ ) $\mathrm{CoN}-\mathrm{S} 2$ negatively biased at -4 $\mathrm{V}$ and (e and f) $\mathrm{CoN}-\mathrm{S} 2$ subsequently positively biased at $+4 \mathrm{~V}$ for $75 \mathrm{~min}$, respectively. Colors corresponding to each element are noted at the bottom of the figure.

were completed (Figure $4 \mathrm{c}-\mathrm{f}$ ) to establish how the film changes under threshold voltage cycling and, to lesser extent, what extent nitrogen is still present in the film, since previous HDAAF-STEM observations made after applying $-50 \mathrm{~V}$ for 75 min showed that all nitrogen had been released to the electrolyte. ${ }^{24}$ After negative biasing of $-4 \mathrm{~V}$ for $75 \mathrm{~min}$, CoNS2 undergoes a very mild change, corresponding to a slightly nanoporous structure near the electrolyte side as well as a decrease in the nitrogen content. Remarkably, under $+4 \mathrm{~V}$ biasing, the film is nearly fully recovered with small nitrogendeficient regions still remaining postrecovery. Additional VEPALS measurements were carried out on FeN-S1 and CoN-S2 (Figure S4) for the as-prepared films, films treated at the onset voltage $(-8$ and $-4 \mathrm{~V}$ for $\mathrm{CoN}$ and $\mathrm{CoN}$, respectively), and films treated at $-50 \mathrm{~V}$. It is observed, postonset treatment, that $\tau_{1}$ remains very similar to the asprepared film (besides the subsurface region, where it increases) while the intensity $I_{1}$ increases slightly across all films. This suggests a very mild increase in the number of local vacancy clusters under onset biasing, consistent with the 
limited removal of $\mathrm{N}$ from the film. Post $-50 \mathrm{~V}$ treatment, a local peak in the intensity of lifetime $\tau_{2}$ (grain boundaries) is observed in both systems, characteristic of a migration front moving through the sample as nitrogen is removed.

To understand the differences in the energetics between iron and cobalt nitrides, $a b$ initio calculation of the energy required to induce ionic motion was performed. Using the nudged elastic band method (NEB) (Methods), minimum energy pathways were calculated for the insertion of a nitrogen atom into an iron slab with hcp FeN structure. The obtained total energy per atom (normalized to the global minimum) is plotted in Figure 5 as a function of the displacement $z$ of the

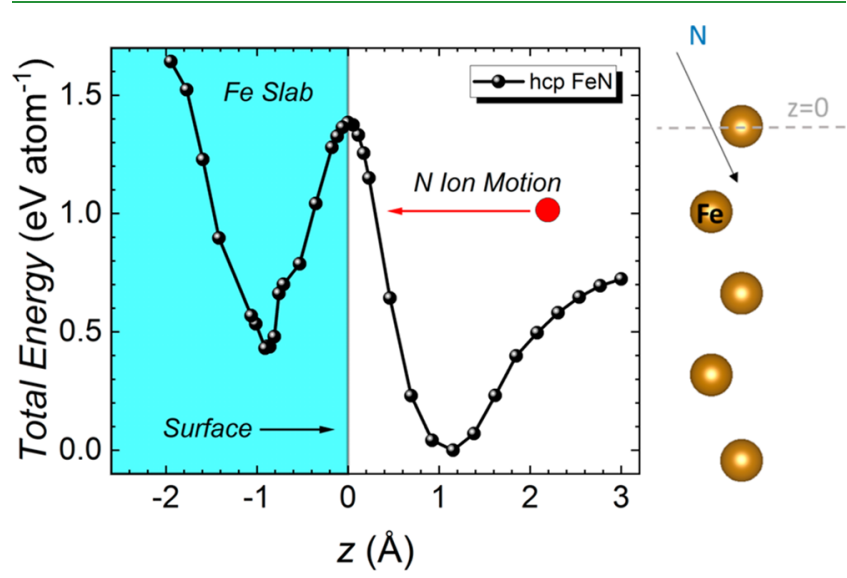

Figure 5. Ab initio calculations of the threshold energy FeN system. Calculated total energy per atom, normalized to the minimum energy value, as a function of the displacement between the outermost $\mathrm{Fe}$ surface atom and the inserted $\mathrm{N}$ atom for both hexagonal closepacked (hcp) structured $\mathrm{Fe}$ slabs. Five-monolayer-thick $\mathrm{Fe}$ slab schematic is shown in the right panel, where the dashed line indicates the reference $z$ position, which is the outermost Fe surface monolayer.

nitrogen atom from the iron reference monolayer (top layer). Setting the outermost iron layer as $z=0 \AA$, the global energy minimum for hcp is found at $z=1.15 \AA$ with another local minimum located around $z=-0.91 \AA$. The critical electric field, $E_{\mathrm{C}}$, can be estimated using the electric potential per atom between minima $\left(1.38 \mathrm{eV}\right.$ atom $\left.^{-1}\right)$ required to move a nitrogen atom between minima, leading to $E_{\mathrm{C}} \approx 6.6 \mathrm{~V} \mathrm{~nm}^{-1}$, similar to the values observed for onset in $\mathrm{FeN}-\mathrm{S} 1$ and $\mathrm{FeN}-$ S2 ( $-8 \mathrm{~V}$, see Figure 4a) and larger (in absolute values) than the critical electrical fields needed to induce nitrogen ion motion in CoN. These results complement recent calculations which show CoN has a lower calculated energy barrier ${ }^{24}$ as well as previous simulations where $\mathrm{FeN}$ was found to have a (slightly) higher cohesive energy than $\mathrm{CoN}^{25,68}$

\section{CONCLUSION}

Magneto-ionics has been demonstrated in single-layer, $85 \mathrm{~nm}$ thick near-stoichiometric FeN films through electrolyte gating, capable of controllably generating and removing a ferromagnetic state (ON-OFF ferromagnetism). The magneto-ionic properties of $\mathrm{FeN}$ are compared with $\mathrm{CoN}$. FeN is found to have a greater total magnetization, a higher coercivity, and a lower rate of magnetization generation under larger bias as well as a higher onset voltage than the examined cobalt nitrides. The available open volume supporting ion transport is slightly lower for $\mathrm{FeN}$ as indicated by PALS. Ab initio calculations show that the formation energy of $\mathrm{FeN}$ requires a greater onset voltage $\left(\approx 6.6 \mathrm{~V} \mathrm{~nm}^{-1}\right)$ to induce magneto-ionic motion than CoN $\left(\approx 5.3 \mathrm{~V} \mathrm{~nm}^{-1}\right)$. The larger total magnetization and coercivity achieved upon biasing show iron-based nitrides are a viable material for magneto-ionic applications and appealing as potential materials in existing nitride semiconductor devices and memory system architectures.

\section{METHODS}

Sample Preparation. Eighty-five nanometer thick FeN was grown by reactive sputtering on boron-doped, highly conducting [100], $500 \mu \mathrm{m}$ thick silicon wafers, previously coated with $20 \mathrm{~nm}$ of titanium and $60 \mathrm{~nm}$ of copper. The copper was masked during deposition to serve as a working electrode.

The expanded FeN films were grown in a homemade triode sputtering system with a base pressure in the range of $10^{-8}$ Torr. Ultrahigh vacuum was ensured to minimize oxygen contamination. The target to substrate distances were around $10 \mathrm{~cm}$, and the sputtering rate was around $1 \AA \mathrm{s}^{-1}$. CoN films were grown in a range of nitrogen partial pressure (100\% $\mathrm{Ar} / 0 \% \mathrm{~N}_{2}, 75 \% \mathrm{Ar} / 25 \% \mathrm{~N}_{2}, 50 \%$ $\mathrm{Ar} / 50 \% \mathrm{~N}_{2}$ ) environments at a total pressure of $8 \times 10^{-3}$ Torr.

Magnetic Characterization. Magneto-electric measurements were performed by vibrating sample magnetometry while electrolyte gating the film in a capacitor-like configuration at room temperature. The films are mounted in a homemade electrolytic cell containing anhydrous propylene carbonate with sodium cation-solvated species $(5 \mathrm{ppm})$. The $\mathrm{Na}^{+}$-solvated species in the electrolyte are present to react with any trace amounts of water in the propylene carbonate. ${ }^{69}$

The magnetic properties of the films were measured in plane while applying different voltages. This was done using a Micro Sense (LOT, Quantum Design) magnetometer with a maximum field of $20 \mathrm{kOe}$. Voltages were applied using an Agilent B2902A power supply between the working electrode and the counter electrode, as demonstrated in previous works. ${ }^{12,61,69}$ The magnetic signal was normalized to the volume exposed to the electrolyte during the gating process. All measured hysteresis loops were background corrected, carried out at high fields (always above the saturation field), to eliminate linear contributions (paramagnetic or diamagnetic signals).

Structural and Compositional Measurements. The $\theta / 2 \theta \mathrm{X}$ ray diffraction patterns were recorded on a Materials Research Diffractometer (MRD) from the Malvern PANalytical Co., equipped with a PIXcel ${ }^{1 \mathrm{D}}$ detector, using $\mathrm{Cu} \mathrm{K} \alpha$ radiation. The XRD patterns were analyzed using Rietveld refinement to obtain lattice cell parameters and crystallite size (average size of coherently diffracting domains)..$^{51}$

High-resolution transmission electron microscopy (HRTEM) high-angle annular dark-field scanning transmission electron microscopy (HDAAF-STEM), and electron energy loss spectroscopy (EELS) were performed on a TECNAI F20 HRTEM/STEM microscope operated at $200 \mathrm{kV}$. Cross-sectional lamellae were prepared by focused ion beam, capped with a sacrificial platinum layer, and placed onto a $\mathrm{Cu}$ transmission electron microscopy grid.

Transport Measurements. Both cobalt nitride and iron nitride films were deposited onto high-resistivity Si substrates. Resistivity values were acquired from 30 to $300 \mathrm{~K}$, all using the van der Pauw configuration.

Variable Energy Positron Annihilation Lifetime Spectroscopy. Variable energy positron annihilation lifetime spectroscopy (VEPALS) measurements were performed at the monoenergetic positron source (MePS) at the radiation source ELBE (Electron Linac for beams with high Brilliance and low Emittance) at HelmholtzZentrum Dresden-Rossendorf (Germany). ${ }^{52} \mathrm{~A} \mathrm{CeBr}_{3}$ detector coupled to a digital lifetime spectrometer with homemade software employing a SPDevices ADQ14DC-2X with 14-bit vertical resolution and $2 \mathrm{GS} \mathrm{s}^{-1}$ (gigasamples per second) horizontal resolution was used. The time resolution function was estimated to be about 0.205 ns. The resolution function required for spectrum analysis uses two Gaussian functions with distinct intensities depending on the positron implantation energy, $E_{\mathrm{p}}$, and appropriate energy shifts. All spectra measured contain at least $10^{7}$ counts. 
Ab Initio Calculations. The first-principles calculations were based on the projector-augmented wave $(\mathrm{PAW})^{70}$ method as implemented in the VASP package ${ }^{71-73}$ using the generalized gradient approximation. ${ }^{74}$ The virtual crystal approximation ${ }^{75}$ was used to model the variation of nitrogen per unit cell. To calculate the $\mathrm{Fe}-\mathrm{N}$ formation energy, the nudged elastic band method (NEB) $)^{76,77}$ on the nitrogen pathway into a five-monolayer thick (0001) hexagonal close-packed Fe slab was used. At each step, the atomic coordinates were relaxed until the forces became smaller than $1 \mathrm{meV}^{-1}$. A kinetic energy cutoff of $500 \mathrm{eV}$ was used for the plane-wave basis set $25 \times 25 \times 1$. $k$-point meshes were used to construct the Brillouin zone in the Fe slab in the NEB calculations.

The data used in this article are available from the corresponding authors upon request.

\section{ASSOCIATED CONTENT}

\section{(s) Supporting Information}

The Supporting Information is available free of charge at https://pubs.acs.org/doi/10.1021/acsami.1c06138.

X-ray diffraction patterns of $\mathrm{CoN}$ films, resistivity measurements on $\mathrm{CoN}$ films, positron lifetime experiments for $\mathrm{FeN}$ and $\mathrm{CoN}$ films, hysteresis loops and magnetoelectric data for $\mathrm{CoN}$ films, and magnetoelectric recovery data for FeN films (PDF)

\section{AUTHOR INFORMATION}

\section{Corresponding Authors}

Enric Menéndez - Departament de Física, Universitat Autònoma de Barcelona, Cerdanyola del Valles E-08193, Spain; (ㄷ) orcid.org/0000-0003-3809-2863; Email: enric.menendez@uab.cat

Jordi Sort - Departament de Física, Universitat Autònoma de Barcelona, Cerdanyola del Valles E-08193, Spain; Institució Catalana de Recerca i Estudis Avançats (ICREA), Barcelona E-08010, Spain; 이이이.org/0000-0003-1213-3639; Email: jordi.sort@uab.cat

\section{Authors}

Julius de Rojas - Departament de Física, Universitat Autònoma de Barcelona, Cerdanyola del Valles E-08193, Spain; (1) orcid.org/0000-0002-1206-4744

Joaquín Salguero - IMN-Instituto de Micro y Nanotecnología (CNM-CSIC), Madrid 28760, Spain

Fatima Ibrahim - Univwesity of Grenoble Alpes, CEA, CNRS, Grenoble 38000, France

Mairbek Chshiev - Univwesity of Grenoble Alpes, CEA, CNRS, Grenoble 38000, France; Institut Universitaire de France, Paris 75231, France; (1) orcid.org/0000-0001-92327622

Alberto Quintana - Department of Physics, Georgetown University, Washington, District of Columbia 20057, United States; orcid.org/0000-0002-9813-735X

Aitor Lopeandia - Departament de Física, Universitat Autònoma de Barcelona, Cerdanyola del Valles E-08193, Spain; Catalan Institute of Nanoscience and Nanotechnology (ICN2), Barcelona E-08193, Spain

Maciej O. Liedke - Institute of Radiation Physics, HelmholtzZentrum Dresden-Rossendorf, Dresden 01328, Germany

Maik Butterling - Institute of Radiation Physics, HelmholtzZentrum Dresden-Rossendorf, Dresden 01328, Germany

Eric Hirschmann - Institute of Radiation Physics, HelmholtzZentrum Dresden-Rossendorf, Dresden 01328, Germany

Andreas Wagner - Institute of Radiation Physics, HelmholtzZentrum Dresden-Rossendorf, Dresden 01328, Germany
Llibertat Abad - Institut de Microelectrònica de Barcelona, IMB-CNM (CSIC), Barcelona E-08193, Spain

José L. Costa-Krämer - IMN-Instituto de Micro y Nanotecnología (CNM-CSIC), Madrid 28760, Spain

Complete contact information is available at: https://pubs.acs.org/10.1021/acsami.1c06138

\section{Notes}

The authors declare no competing financial interest.

\section{ACKNOWLEDGMENTS}

Financial support by the European Research Council (SPINPORICS 2014-Consolidator Grant, Agreement No. 648454, and the MAGIC-SWITCH 2019-Proof of Concept Grant, Agreement No. 875018), the Spanish Government (MAT2017-86357-C3-1-R), the Generalitat de Catalunya (2017-SGR-292 and 2018-LLAV-00032), the European Regional Development Fund (MAT2017-86357-C3-1-R and 2018-LLAV-00032), and the French ANR (ANR-18-CE240017 "FEOrgSpin" and ELECSPIN ANR-16-CE24-0018 "ELECSPIN") is acknowledged. This work was partially supported by the Impulse- und Net-working fund of the Helmholtz Association (FKZ VH-VI-442 Memriox) and the Helmholtz Energy Materials Characterization Platform (03ET7015). The PALS measurements were carried out at ELBE at the Helmholtz-Zentrum Dresden-Rossendorf e. V., a member of the Helmholtz Association. We thank the facility staff for assistance. L.A. thanks MINECO for a Ramón y Cajal Contract (RYC-2013-12640).

\section{REFERENCES}

(1) Hu, J. M.; Nan, C. W. Opportunities and Challenges for Magnetoelectric Devices. APL Mater. 2019, 7 (8), 080905.

(2) Song, C.; Cui, B.; Li, F.; Zhou, X.; Pan, F. Recent Progress in Voltage Control of Magnetism: Materials, Mechanisms, and Performance. Prog. Mater. Sci. 2017, 87, 33-82.

(3) Vasala, S.; Jakob, A.; Wissel, K.; Waidha, A. I.; Alff, L.; Clemens, O. Reversible Tuning of Magnetization in a Ferromagnetic Ruddlesden-Popper-Type Manganite by Electrochemical FluorideIon Intercalation. Adv. Electron. Mater. 2020, 6 (2), 1900974.

(4) Tan, A. J.; Huang, M.; Sheffels, S.; Büttner, F.; Kim, S.; Hunt, A. H.; Waluyo, I.; Tuller, H. L.; Beach, G. S. D. Hydration of Gadolinium Oxide (Gd Ox) and Its Effect on Voltage-Induced Co Oxidation in a $\mathrm{Pt} / \mathrm{Co} / \mathrm{Gd} \mathrm{Ox} / \mathrm{Au}$ Heterostructure. Phys. Rev. Mater. 2019, 3 (6), 064408.

(5) de Rojas, J.; Quintana, A.; Lopeandía, A.; Salguero, J.; CostaKrämer, J. L.; Abad, L.; Liedke, M. O.; Butterling, M.; Wagner, A.; Henderick, L.; Dendooven, J.; Detavernier, C.; Sort, J.; Menéndez, E. Boosting Room-Temperature Magneto-Ionics in a Non-Magnetic Oxide Semiconductor. Adv. Funct. Mater. 2020, 30 (36), 2003704.

(6) Dasgupta, S.; Das, B.; Li, Q.; Wang, D.; Baby, T. T.; Indris, S.; Knapp, M.; Ehrenberg, H.; Fink, K.; Kruk, R.; Hahn, H. Toward Onand-Off Magnetism: Reversible Electrochemistry to Control Magnetic Phase Transitions in Spinel Ferrites. Adv. Funct. Mater. 2016, 26 (41), $7507-7515$.

(7) Dasgupta, S.; Das, B.; Knapp, M.; Brand, R. A.; Ehrenberg, H.; Kruk, R.; Hahn, H. Intercalation-Driven Reversible Control of Magnetism in Bulk Ferromagnets. Adv. Mater. 2014, 26 (27), 4639-4644.

(8) Bauer, U.; Yao, L.; Tan, A. J.; Agrawal, P.; Emori, S.; Tuller, H. L.; Van Dijken, S.; Beach, G. S. D. Magneto-Ionic Control of Interfacial Magnetism. Nat. Mater. 2015, 14 (2), 174-181.

(9) Baldrati, L.; Tan, A. J.; Mann, M.; Bertacco, R.; Beach, G. S. D. Magneto-Ionic Effect in $\mathrm{CoFeB}$ Thin Films with in-Plane and 
Perpendicular-to-Plane Magnetic Anisotropy. Appl. Phys. Lett. 2017, 110 (1), 012404.

(10) Navarro-Senent, C.; Fornell, J.; Isarain-Chávez, E.; Quintana, A.; Menéndez, E.; Foerster, M.; Aballe, L.; Weschke, E.; Nogués, J.; Pellicer, E.; Sort, J. Large Magnetoelectric Effects in Electrodeposited Nanoporous Microdisks Driven by Effective Surface Charging and Magneto-Ionics. ACS Appl. Mater. Interfaces 2018, 10 (51), 4489744905.

(11) Tan, A. J.; Huang, M.; Avci, C. O.; Büttner, F.; Mann, M.; Hu, W.; Mazzoli, C.; Wilkins, S.; Tuller, H. L.; Beach, G. S. D. MagnetoIonic Control of Magnetism Using a Solid-State Proton Pump. Nat. Mater. 2019, 18 (1), 35-41.

(12) Quintana, A.; Menéndez, E.; Liedke, M. O.; Butterling, M.; Wagner, A.; Sireus, V.; Torruella, P.; Estradé, S.; Peiró, F.; Dendooven, J.; Detavernier, C.; Murray, P. D.; Gilbert, D. A.; Liu, K.; Pellicer, E.; Nogues, J.; Sort, J. Voltage-Controlled ON-OFF Ferromagnetism at Room Temperature in a Single Metal Oxide Film. ACS Nano 2018, 12 (10), 10291-10300.

(13) Molinari, A.; Hahn, H.; Kruk, R. Voltage-Control of Magnetism in All-Solid-State and Solid/Liquid Magnetoelectric Composites. Adv. Mater. 2019, 31 (26), 1806662.

(14) Ibrahim, F.; Hallal, A.; Dieny, B.; Chshiev, M. Establishing Characteristic Behavior of Voltage Control of Magnetic Anisotropy by Ionic Migration. Phys. Rev. B: Condens. Matter Mater. Phys. 2018, 98 (21), 214441.

(15) Gößler, M.; Albu, M.; Klinser, G.; Steyskal, E. M.; Krenn, H.; Würschum, R. Magneto-Ionic Switching of Superparamagnetism. Small 2019, 15 (46), 1904523.

(16) Gilbert, D. A.; Olamit, J.; Dumas, R. K.; Kirby, B. J.; Grutter, A. J.; Maranville, B. B.; Arenholz, E.; Borchers, J. A.; Liu, K. Controllable Positive Exchange Bias via Redox-Driven Oxygen Migration. Nat. Commun. 2016, 7, 11050.

(17) Gilbert, D. A.; Grutter, A. J.; Arenholz, E.; Liu, K.; Kirby, B. J.; Borchers, J. A.; Maranville, B. B. Structural and Magnetic Depth Profiles of Magneto-Ionic Heterostructures beyond the Interface Limit. Nat. Commun. 2016, 7, 12264.

(18) Duschek, K.; Uhlemann, M.; Schlörb, H.; Nielsch, K.; Leistner, K. Electrochemical and in Situ Magnetic Study of Iron/Iron Oxide Films Oxidized and Reduced in $\mathrm{KOH}$ Solution for Magneto-Ionic Switching. Electrochem. Commun. 2016, 72, 153-156.

(19) Wolf, S. A.; Awschalom, D. D.; Buhrman, R. A.; Daughton, J. M.; von Molnár, S.; Roukes, M. L.; Chtchelkanova, A. Y.; Treger, D. M. Spintronics: A Spin-Based Electronics Vision for the Future. Science 2001, 294 (5546), 1488-1495.

(20) Eerenstein, W.; Mathur, N. D.; Scott, J. F. Multiferroic and Magnetoelectric Materials. Nature 2006, 442, 759-765.

(21) Duschek, K.; Petr, A.; Zehner, J.; Nielsch, K.; Leistner, K. AllElectrochemical Voltage-Control of Magnetization in Metal Oxide/ Metal Nanoislands. J. Mater. Chem. C 2018, 6 (31), 8411-8417.

(22) Bi, C.; Liu, Y.; Newhouse-Illige, T.; Xu, M.; Rosales, M.; Freeland, J. W.; Mryasov, O.; Zhang, S.; Te Velthuis, S. G. E.; Wang, W. G. Reversible Control of Co Magnetism by Voltage-Induced Oxidation. Phys. Rev. Lett. 2014, 113 (26), 267202.

(23) Cialone, M.; Nicolenco, A.; Robbennolt, S.; Menéndez, E.; Rius, G.; Sort, J. Voltage-Induced ON Switching of Magnetism in Ordered Arrays of Non-Ferrimagnetic Nanoporous Iron Oxide Microdisks. Adv. Mater. Interfaces 2021, 8 (1), 2001143.

(24) de Rojas, J.; Quintana, A.; Lopeandía, A.; Salguero, J.; Muñiz, B.; Ibrahim, F.; Chshiev, M.; Nicolenco, A.; Liedke, M. O.; Butterling, M.; Wagner, A.; Sireus, V.; Abad, L.; Jensen, C. J.; Liu, K.; Nogués, J.; Costa-Krämer, J. L.; Menéndez, E.; Sort, J. Voltage-Driven Motion of Nitrogen Ions: A New Paradigm for Magneto-Ionics. Nat. Commun. 2020, 11 (1), 5871.

(25) Häglund, J.; Fernández Guillermet, A.; Grimvall, G.; Körling, M. Theory of Bonding in Transition-Metal Carbides and Nitrides. Phys. Rev. B: Condens. Matter Mater. Phys. 1993, 48 (16), 1168511691.

(26) Robie, R.; Hemingway, B. S. Thermodynamic Properties of Minerals and Related Substances at $298.15 \mathrm{~K}$ and 1 bar (10-5
Pascals) Pressure and at Higher Temperatures. U.S. Geol. Surv. Bull. 1995, 1-461.

(27) Glasser, L.; Sheppard, D. A. Cohesive Energies and Enthalpies: Complexities, Confusions, and Corrections. Inorg. Chem. 2016, 55 (14), 7103-7110.

(28) Chase, M. NIST-JANAF Thermochemical Tables, 4th ed.; American Institute of Physics, 1998.

(29) Tessier, F.; Navrotsky, A.; Niewa, R.; Leineweber, A.; Jacobs, H.; Kikkawa, S.; Takahashi, M.; Kanamaru, F.; DiSalvo, F. J. Energetics of Binary Iron Nitrides. Solid State Sci. 2000, 2 (4), $457-462$.

(30) Coey, J. M. D.; Smith, P. A. I. Magnetic Nitrides. J. Magn. Magn. Mater. 1999, 200 (1-3), 405-424.

(31) Jhi, S. H.; Louie, S. G.; Cohen, M. L.; Morris, J. W. Mechanical Instability and Ideal Shear Strength of Transition Metal Carbides and Nitrides. Phys. Rev. Lett. 2001, 87 (7), 075503.

(32) Wriedt, H. A.; Gokcen, N. A.; Nafziger, R. H. The Fe-N (IronNitrogen) System. Bull. Alloy Phase Diagrams 1987, 8 (4), 355-377.

(33) Jack, K. H. Binary and Ternary Interstitial Alloys I. The IronNitrogen System: The Structures of Fe $4 \mathrm{~N}$ and Fe 2 N. Proc. R. Soc. London, Ser. A. Math. Phys. Sci. 1948, 195 (1040), 34-40.

(34) Jack, K. H. The Occurrence and the Crystal Structure of $\alpha$ "Iron Nitride; a New Type of Interstitial Alloy Formed during the Tempering of Nitrogen-Martensite. Proc. R. Soc. London, Ser. A. Math. Phys. Sci. 1951, 208 (1093), 216-224.

(35) Jack, K. H. The Iron-Nitrogen System: The Crystal Structures of $\alpha$-Phase Iron Nitrides. Acta Crystallogr. 1952, 5 (4), 404-411.

(36) Jack, K. H. Results of Further X-Ray Structural Investigations of the Iron-Carbon and Iron-Nitrogen Systems and of Related Interstitial Alloys. Acta Crystallogr. 1950, 3 (5), 392-394.

(37) Kardonina, N. I.; Yurovskikh, A. S.; Kolpakov, A. S. Transformations in the Fe - N System. Met. Sci. Heat Treat. 2011, 52 (9-10), 457-467.

(38) Zhang, Y.; Wang, Q. Magnetic-Plasmonic Dual Modulated FePt-Au Ternary Heterostructured Nanorods as a Promising NanoBioprobe. Adv. Mater. 2012, 24 (18), 2485-2490.

(39) Zhang, X.; Yang, M.; Jiang, Y.; Allard, L. F.; Wang, J. P. Thermal Stability of Partially Ordered Fe16N2 Film on NonMagnetic Ag under Layer. J. Appl. Phys. 2014, 115 (17), 17A767.

(40) Mahmoudi, M.; Shokrgozar, M. A. Multifunctional Stable Fluorescent Magnetic Nanoparticles. Chem. Commun. 2012, 48, 3957-3959.

(41) Liu, J.; Zhang, Q.; Yu, H.; Sun, F. Magnetic Properties of the Ising Ferromagnetic Iron Nitride System. J. Magn. Magn. Mater. 2005, $288,48-53$.

(42) Hang, X.; Matsuda, M.; Held, J. T.; Mkhoyan, K. A.; Wang, J. P. Magnetic Structure of Fe16 N2 Determined by Polarized Neutron Diffraction on Thin-Film Samples. Phys. Rev. B: Condens. Matter Mater. Phys. 2020, 102 (10), 104402.

(43) Pavanati, H. C.; Straffelini, G.; Maliska, A. M.; Klein, A. N. Dry Sliding of Plasma-Sintered Iron-The Influence of Nitriding on Wear Resistance. Wear 2008, 265 (3-4), 301-310.

(44) Mohn, P.; Matar, S. F. The $\gamma$-Fe4N System Revisited: An Ab Initio Calculation Study of the Magnetic Interactions. J. Magn. Magn. Mater. 1999, 191 (1-2), 234-240.

(45) Gupta, M.; Tayal, A.; Gupta, A.; Gupta, R.; Stahn, J.; Horisberger, M.; Wildes, A. Iron and Nitrogen Self-Diffusion in NonMagnetic Iron Nitrides. J. Appl. Phys. 2011, 110, 123518.

(46) Chen, H. T.; Yan, M. F.; You, Y. Effect of N Distribution on Elastic and Electronic Properties of Hexagonal $\varepsilon$-Fe6Nx by FirstPrinciples Calculations. J. Magn. Magn. Mater. 2014, 354, 200-204.

(47) Matar, S. F.; Demazeau, G.; Siberchicot, B. Magnetic Particles Derived from Iron Nitride. IEEE Trans. Magn. 1990, 26 (1), 60-62.

(48) In CRC Handbook of Chemistry and Physics, 97th ed.; Rumble, J. R., Ed.; CRC Press, 2016.

(49) Jain, A.; Ong, S. P.; Hautier, G.; Chen, W.; Richards, W. D.; Dacek, S.; Cholia, S.; Gunter, D.; Skinner, D.; Ceder, G.; Persson, K. A. Commentary: The Materials Project: A Materials Genome 
Approach to Accelerating Materials Innovation. APL Mater. 2013, 1 (1), 011002

(50) Mader, K. H.; Thieme, F.; Knappwost, A. Magnetische Eigenschaften Der Kobalt-Stickstoff-Phase Co3N. Z. Anorg. Allg. Chem. 1969, 366 (5-6), 274-279.

(51) Lutterotti, L.; Scardi, P. Simultaneous Structure and Size-Strain Refinement by the Rietveld Method. J. Appl. Crystallogr. 1990, 23 (4), 246-252.

(52) Wagner, A.; Butterling, M.; Liedke, M. O.; Potzger, K.; KrauseRehberg, R. Positron Annihilation Lifetime and Doppler Broadening Spectroscopy at the ELBE Facility. AIP Conf. Proc. 2017, 1970, 040003.

(53) Wada, K.; Hyodo, T. A Simple Shape-Free Model for Pore-Size Estimation with Positron Annihilation Lifetime Spectroscopy. J. Phys. Conf. Ser. 2013, 443, 012003.

(54) Tuomisto, F.; Makkonen, I. Defect Identification in Semiconductors with Positron Annihilation: Experiment and Theory. Rev. Mod. Phys. 2013, 85 (4), 1583.

(55) Olsen, J. V.; Kirkegaard, P.; Pedersen, N. J.; Eldrup, M. PALSfit: A New Program for the Evaluation of Positron Lifetime Spectra. Phys. Status Solidi C 2007, 4 (10), 4004-4006.

(56) Liedke, M. O.; Anwand, W.; Bali, R.; Cornelius, S.; Butterling, M.; Trinh, T. T.; Wagner, A.; Salamon, S.; Walecki, D.; Smekhova, A.; Wende, H.; Potzger, K. Open Volume Defects and Magnetic Phase Transition in Fe60A140 Transition Metal Aluminide. J. Appl. Phys. 2015, 117, 163908.

(57) Krause-Rehberg, R.; Leipner, H. S. Positron Annihilation in Semiconductors; Springer Series in Solid-State Sciences; Springer: Berlin Heidelberg, 1999; Vol. 127, p 383.

(58) Weisheit, M.; Fähler, S.; Marty, A.; Souche, Y.; Poinsignon, C.; Givord, D. Electric Field-Induced Modification of Magnetism in Thin-Film Ferromagnets. Science 2007, 315 (5810), 349-351.

(59) Robbennolt, S.; Nicolenco, A.; Mercier Fernandez, P.; Auffret, S.; Baltz, V.; Pellicer, E.; Menéndez, E.; Sort, J. Electric Field Control of Magnetism in Iron Oxide Nanoporous Thin Films. ACS Appl. Mater. Interfaces 2019, 11 (40), 37338-37346.

(60) Robbennolt, S.; Menéndez, E.; Quintana, A.; Gómez, A.; Auffret, S.; Baltz, V.; Pellicer, E.; Sort, J. Reversible, Electric-Field Induced Magneto-Ionic Control of Magnetism in Mesoporous Cobalt Ferrite Thin Films. Sci. Rep. 2019, 9, 10804.

(61) Navarro-Senent, C.; Quintana, A.; Menéndez, E.; Pellicer, E.; Sort, J. Electrolyte-Gated Magnetoelectric Actuation: Phenomenology, Materials, Mechanisms, and Prospective Applications. APL Mater. 2019, 7 (3), 030701.

(62) Leighton, C. Electrolyte-Based Ionic Control of Functional Oxides. Nat. Mater. 2019, 18, 13-18.

(63) Soni, H. R.; Mankad, V.; Gupta, S. K.; Jha, P. K. A First Principles Calculations of Structural, Electronic, Magnetic and Dynamical Properties of Mononitrides FeN and CoN. J. Alloys Compd. 2012, 522, 106-113.

(64) Matar, S.; Mohn, P. Electronic and Magnetic Properties of Fe2N and FeN: Trends of The Magnetism of the Fe-N System. Act. Passive Electron. Compon. 1993, 15 (2), 89-101.

(65) Leslie-Pelecky, D. L.; Rieke, R. D. Magnetic Properties of Nanostructured Materials. Chem. Mater. 1996, 8, 1770-1783.

(66) Allred, A. L. Electronegativity Values from Thermochemical Data. J. Inorg. Nucl. Chem. 1961, 17 (3-4), 215-221.

(67) Mann, J. B.; Meek, T. L.; Knight, E. T.; Capitani, J. F.; Allen, L. C. Configuration Energies of the D-Block Elements. J. Am. Chem. Soc. 2000, 122 (21), 5132-5137.

(68) Liu, Z. T. Y.; Zhou, X.; Khare, S. V.; Gall, D. Structural, Mechanical and Electronic Properties of 3d Transition Metal Nitrides in Cubic Zincblende, Rocksalt and Cesium Chloride Structures: A First-Principles Investigation. J. Phys.: Condens. Matter 2014, 26, 025404.

(69) Quintana, A.; Zhang, J.; Isarain-Chávez, E.; Menéndez, E.; Cuadrado, R.; Robles, R.; Baró, M. D.; Guerrero, M.; Pané, S.; Nelson, B. J.; Müller, C. M.; Ordejón, P.; Nogués, J.; Pellicer, E.; Sort, J. Voltage-Induced Coercivity Reduction in Nanoporous Alloy Films:
A Boost toward Energy-Efficient Magnetic Actuation. Adv. Funct. Mater. 2017, 27 (32), 1701904.

(70) Blöchl, P. E. Projector Augmented-Wave Method. Phys. Rev. B: Condens. Matter Mater. Phys. 1994, 50 (24), 17953-17979.

(71) Kresse, G.; Furthmüller, J. Efficient Iterative Schemes for $\mathrm{Ab}$ Initio Total-Energy Calculations Using a Plane-Wave Basis Set. Phys. Rev. B: Condens. Matter Mater. Phys. 1996, 54 (16), 11169-11186.

(72) Kresse, G.; Furthmüller, J. Efficiency of Ab-Initio Total Energy Calculations for Metals and Semiconductors Using a Plane-Wave Basis Set. Comput. Mater. Sci. 1996, 6 (1), 15-50.

(73) Kresse, G.; Hafner, J. Ab Initio Molecular Dynamics for Liquid Metals. Phys. Rev. B: Condens. Matter Mater. Phys. 1993, 48 (17), 13115-13118.

(74) Perdew, J. P.; Burke, K.; Ernzerhof, M. Generalized Gradient Approximation Made Simple. Phys. Rev. Lett. 1996, 77 (18), 38653868.

(75) Bellaiche, L.; Vanderbilt, D. Virtual Crystal Approximation Revisited: Application to Dielectric and Piezoelectric Properties of Perovskites. Phys. Rev. B: Condens. Matter Mater. Phys. 2000, 61 (12), $7877-7882$.

(76) Henkelman, G.; Jónsson, H. Improved Tangent Estimate in the Nudged Elastic Band Method for Finding Minimum Energy Paths and Saddle Points. J. Chem. Phys. 2000, 113 (22), 9978-9985.

(77) Henkelman, G.; Uberuaga, B. P.; Jónsson, H. Climbing Image Nudged Elastic Band Method for Finding Saddle Points and Minimum Energy Paths. J. Chem. Phys. 2000, 113 (22), 9901-9904. 